\title{
Marae-opoly: supporting localised Māori climate adaptation decisions with serious games in Aotearoa New Zealand
}

\author{
Paula Blackett ${ }^{1} \cdot$ Stephen FitzHerbert $^{1} \cdot$ Jordan Luttrell $^{1} \cdot$ Tania Hopmans $^{2} \cdot$ Hayley Lawrence $^{2} \cdot$ Jackie Colliar $^{1,3}$
}

Received: 16 February 2021 / Accepted: 30 June 2021 / Published online: 10 August 2021

(c) The Author(s) 2021

\begin{abstract}
Far from being passive and/or static victims of climate change, indigenous peoples are hybridizing knowledge systems, and challenging and negotiating new environmental and social realities to develop their own adaptation options within their own registers of what is place and culture appropriate. Our paper seeks to demonstrate how we, as guests on Māori land, were able to develop a partnership with a Māori community facing difficult adaptation decisions regarding climate change hazards through the pragmatic navigation of multi-disciplinary research and practice. In particular, we co-developed and tested the potential of a serious game (Marae-opoly) approach as a platform which assembles cross-cultural climate change knowledge to learn, safely experiment and inform adaptation decisions. Marae-opoly was developed bespoke to its intended context - to support the creation of mutually agreeable dynamic adaptive policy pathways (DAPP) for localized flood adaptation. Game material was generated by drawing together detailed local knowledge (i.e. hydrology, climate data, mātauranga hapū) and situated adaptation options and accurate contextual data to create a credible gaming experience for the hapu of Tangoio Marae. We argue that the in-situ co-development process used to co-create Marae-opoly was fundamental in its success in achieving outcomes for the hapū. It also provided important lessons for the research team regarding how to enter as respectful guests and work together effectively to provide a resource to support our partners' adaptation decisions. The paper discusses the steps taken to establish research partnerships and develop the serious game and its subsequent playing, albeit we do not evaluate our indigenous research partners' adaptation decisions. Our contribution with this paper is in sharing an approach which cultivated the ground to enter as respectful guests and work together effectively to provide a resource for our partners' adaptation decisions.
\end{abstract}

Keywords Serious games $\cdot$ Indigenous climate change adaptation $\cdot$ Engaging with indigenous peoples $\cdot$ Guests $\cdot$ Dynamic Adaptive Policy Pathways (DAPP) · Flood adaptation

\section{Introduction}

Impacts of climate change will be disproportionately experienced by Māori across Aotearoa-New Zealand due to the pervasive impacts of a changing climate on their assets, interests, kawa (protocols) and tikanga (correct procedures,

Handled by Kirsten Maclean, CSIRO, Australia.

Paula Blackett

paula.blackett@niwa.co.nz

1 National Institute of Water and Atmosphere Research (NIWA), PO Box 11115, Hamilton 3251, New Zealand

2 Maungaharuru-Tangitū Trust, Napier, New Zealand

3 Hamilton City Council, Hamilton, New Zealand lore, practises) and expressions of mana (authority, dignity, control, governance, power) and kaitiakitanga (intergenerational sustainability) (Ministry for the Environment 2020). The situation of Māori is shared with many indigenous peoples around the world due to various consequences of colonial processes (Ford et al. 2012; Leonard et al. 2013). Measures to adapt to climate change are likely to raise social and cultural issues for Māori (Parsons et al. 2019). 
The challenge is coupled with asymmetries between climate change research and its distributional reach as well as the articulation of western climate change knowledge with indigenous knowledges (UN 2009; Ford et al. 2012; Klenk et al. 2017). It is imperative these issues be understood, acknowledged, and negotiated so that responses to the potential impacts of climate change on critical services for Māori communities such as cultural assets (e.g., Marae buildings and structures) and critical infrastructure, water management and public health, are aligned with the values of the people they are intended to help and avoid reproducing existing inequalities (King et al. 2013; Klenk et al. 2017; Ford et al. 2020). As such, there is an urgent need for processes and practices that respond to the adaptation challenge ahead yet remain cognizant of the need to navigate adaptation through a Māori centric lens. The objective is to empower Māori iwi/hapū (kinship groupings including hapū or whānau, and whanau, respectively) decision-makers to register climate change knowledge within their own metrics to support their decision-making processes in accordance with their own values, practices, and aspirations. With this paper, we aim to support the bringing into being of postcolonial worlds (Ministry for the Environment 2018).

Our paper explores the potential of a serious games approach as a platform which assembles cross-cultural climate change knowledge to learn, safely experiment and inform adaptation decisions. The paper discusses the steps taken to establish research partnerships and co-develop the serious game and its subsequent playing; albeit we do not evaluate our indigenous research partners' adaptation decisions. Further, the data that informed the game development is not presented (the reader is directed to Colliar and Blackett 2018 for that detail) we focus on the process rather than the content. Our contribution with this paper is in sharing an approach which cultivated the ground to enter as respectful guests to collaborate effectively and co-develop a resource for our partners' adaptation decisions.

We argue that in-situ co-development of serious games with indigenous groups, fosters the opportunity to empower the weaving of indigenous and non-indigenous practices and knowledges to develop situated understandings and responses to climate change hazards. We evidence this argument by addressing three research questions: Does the codevelopment process create a realistic game that reflects the hapū's reality? Did the serious game (Marae-opoly) create a safe learning and experimental space for the hapu that is attentive to both culture and place? Was the game a useful and appropriate way to explore knowledges, perspectives, and alternatives in a way that is empowering? Our objective with answering these questions is to share a story that can inform, what we consider, useful practices for fostering respectful and productive partnerships with indigenous peoples which support efforts of adapting to climate change in place.

Our specific aim is to register specific material that considers climate change adaptation issues for Māori. In the first section, we discuss the theoretical and political underpinnings of developing a serious game for a Māori community. We then explain our research methodology, in detail. In the third section, we present our results. Fourth, we examine our findings and reflect on their value to inform the development of serious games with a Māori community and supporting place-based learning and adaptation planning (on the marae). We conclude with an overall proposition for developing indigenous serious games and provide insights into the creation of research partnerships to enact co-production of knowledge with indigenous peoples.

\section{Theoretical background: a serious games approach to indigenous climate change adaptation}

It is well documented that the resolution of "wicked" real-world problems requires the application of diverse knowledges through trans-disciplinary tools, processes, and practices (de Coninck et al. 2018). Our paper seeks to demonstrate how we worked in partnership with a Māori community facing difficult adaptation decisions regarding climate change hazards through pragmatic navigation of multi-disciplinary research and practice. In doing so, we draw on ideas of knowledge and practice from climate change adaptation, principally Dynamic Adaptive Policy Pathways (DAPP) (Haasnoot et al. 2013; Lawrence et al. 2019) planning, serious games, and engaging with indigenous peoples.

\section{Climate change adaptation}

Adaptation to climate change is the process of adjustment to the actual or expected effects of a changing climate on human systems (IPCC 2018). Adjustments may encompass activities that accommodate change, protect assets, retreat from the hazard or avoid existing and new risks (Rouse et al. 2016), which can be undertaken often in combination and staged over time (Bell et al. 2017; Barnett et al. 2014; Lawrence et al. 2019). Put simply, the purpose of adaptation is to moderate or avoid any risks, and to utilise any potential benefits from the changing climate to individuals, whānau, hapū, communities, and businesses while facilitating the retention of things (objects or practices) of value and importance into the future (Barnett et al. 2014; Rouse et al. 2016; Tschakert et al. 2017). Navigation of the various options over time against a backdrop of accelerating, compounding, and cascading climate change hazards and risk (Lawrence 


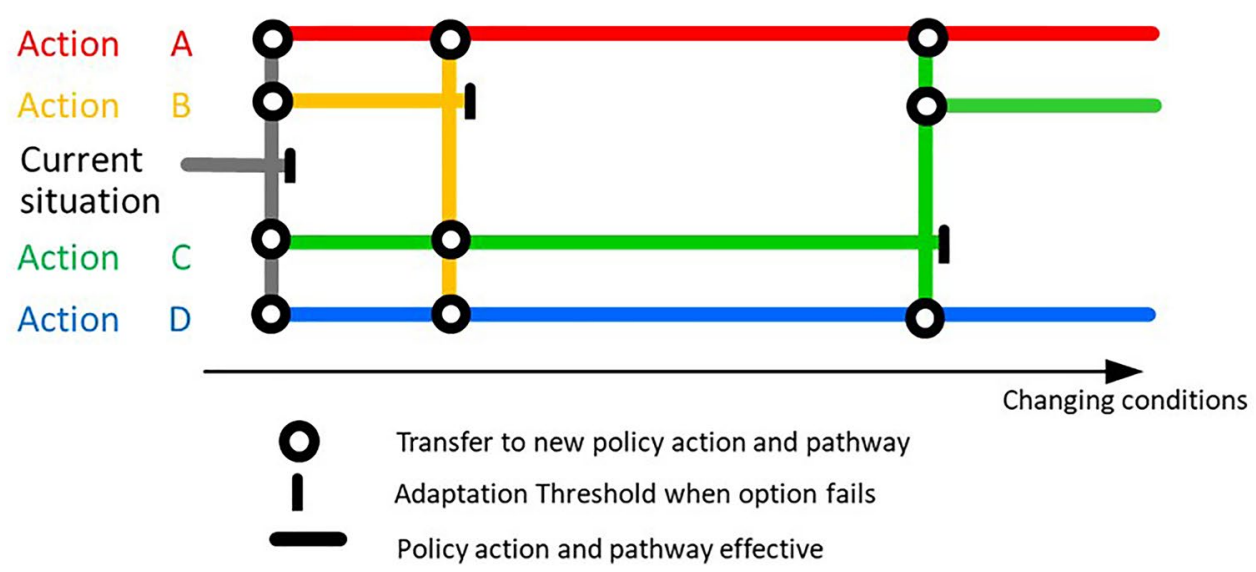

Fig. 1 A generic adaptation pathway ( Adapted from Haasnoot et al. (2013). Adaptation options are listed along the $y$ axis and changing conditions are on the $x$ axis. Each option has a lifetime at which point it is no longer effective given the changing conditions. The length of the line denotes the longevity of each option while the circles illustrate where one option can be successfully transitioned to another.

et al. 2020) is where DAPP is a useful tool (Haasnoot et al. 2013; Lawrence et al. 2019). Rather than try and predict the future, DAPP presents a way of considering a range of possible options that could be implemented over time as change occurs.

This means that adaptation choices are mapped out in advance (Fig. 1) and implemented when they are needednot too early and not too late (Lawrence et al 2019). Previous research has successfully combined a serious game and a DAPP design process to catalyse a change in mindset in decision-makers in a local government context (Lawrence and Haasnoot 2017). However, building a game to support a DAPP design process has not been applied in an indigenous context coupled with applying co-development principles.

Indigenous peoples worldwide share deep social, cultural, and spiritual ties to their lands and are as such exposed to multiple and diverse challenges of a changing climate (UN 2009; Ford et al. 2012; de Coninck et al. 2018). Far from being passive and/or static victims of climate change, indigenous peoples are improvising, learning, hybridizing knowledge systems, and challenging and negotiating new environmental and social realities to develop their own adaptation options within their own registers of what is place and culture appropriate (UN 2009). There is an emergent literature on the field of climate change adaptation and hazard risk reduction amongst indigenous groups (Ford et al. 2012; Leonard et al. 2013; Hiwasaki et al. 2015; Lambert and Scott 2019; Hill et al. 2020). Shared across nearly all accounts, these authors provide multiple examples of how positive and empowering transformational change from colonial legacies can root in; although, they strongly warn against the practices which reproduce inequalities and negatively
Movement through the diagram between options can occur in a variety of ways which do not need to be predetermined but can respond to changing conditions. The "pathways" taken between the options as the climate changes may vary and will be a product of social, cultural, and economic factors

influence adaptation decisions (see, Hiwasaki et al. 2015; Whyte 2018; Ford et al. 2020). While each indigenous experience is different, consensus can be drawn on the basis that climate change from an indigenous perspective is broader and more encompassing than typical non-indigenous realities and understandings. This a result of the combination of direct changes and the multiple cultural considerations and strong (and long) attachment to place (Makondo and Thomas 2018), which constitutes indigenous ways of being and living with the environment. These include considerations such as how a changing climate will affect interpersonal and environmental relationships, life experience, spiritual considerations, family, kinship, and oral history (see also, Leonard et al. 2013; Whyte 2018). As such, multiple authors argue that for climate change adaptation and hazard management pathways to be effective, research practices must be adapted for indigenous communities and respect indigenous approaches and empower the expression and rights of selfdetermination. Such practices may include (though are not limited to): coordinating alliances; culturally appropriate incentives; accurate, appropriate, and ethical data collection; acknowledgment of indigenous land-use practices; use of indigenous language, leadership, and institutions; and, respectful collaboration with indigenous knowledges (Lambert and Scott 2019; see also, Parsons et al 2016; Hill et al. 2020; Ford et al. 2020).

The following draws together key lessons from authors who attend to the concepts of co-production and partnership with indigenous peoples. The approach is a commitment to decolonise research processes (Barker and Pickerill 2020). Hill et al. (2020) suggest indigenous adaptation pathways are likely to be more effective (and ethical) when 
non-indigenous and indigenous knowledge is co-produced, as it better articulates knowledge and constitutes more suitable adaptation options which are situated by and according to indigenous peoples values and their traditional lands (see also, Klenk et al. 2017; Zurba et al. 2019; Latulippe and Klenk 2020). They warn, however, that ignoring the complex and contested histories of both place and relationships with indigenous peoples (see, Smith 1999) results in naïve adaptation plans which may increase vulnerability to hazards, as well as re-establish prior colonial relationships. Hill et al. (2020) suggest that the co-development of knowledge and place-based adaptation pathways for indigenous peoples is underpinned by methods based upon deeply respectful partnerships and cultural governance; indigenous people have an ongoing connection to their traditional places to maintain their indigenous knowledge; and, the relationship between the indigenous people and the nation-state empowers local decision-making and learning, which requires and creates consent, trust, accountability, reciprocity, and resurgence of indigenous culture, knowledge, and practices (see also, Parsons et al. 2016). Furthermore, as Lattulippe and Klenk (2020) warn, researchers working with indigenous peoples must be sensitive to avoid notions of knowledge integration within co-production processes as these present consequences for protecting indigenous sovereignty of knowledge. They suggest, researchers should be open to giving themselves (and projects) up to leadership from indigenous peoples in research programmes. Parsons et al. (2016) suggest the researchers should attend to co-designing programmes with indigenous peoples which enable inclusive approaches of transformation which include (at the least) indigenous ontologies and epistemologies. Partnership with indigenous peoples in research, should be wary and take its direction from such groups.

When partnering with indigenous peoples it is critical to deeply consider the social and cultural context of partnerships, knowledge production, and decision-making processes (Latulippe and Klenk 2020; Gorddard et al. 2016; Granderson 2014). Each indigenous group has a unique context is unique as too are their aspirations and decisions in relation to adapting to climate change and environmental hazards and maintaining sovereignty over their knowledge and decisions. Essentialised and generalised notions of indigenous do not work. We have aimed to draw widely from the current efforts of researchers working in this area, with the intention of bringing lessons into our own context as well as providing a repository of literature within the text and reference list of our paper, which may support the endeavours of those researchers more appropriately placed.

\section{Serious games}

Serious games are an innovative participatory approach to stimulate and foster action as they integrate technical-physical and socio-political complexity for participants to learn and test alternative strategies to achieve desirable outcomes (Medema et al. 2016; den Hann and Voort 2018; Wesselow and Stoll-Kleemann 2018; Bathke et al. 2019). Game-based approaches have been used to facilitate knowledge and action in natural resource governance, and climate change adaptation (Flood et al. 2018). Further, games are credited with generating tangible results compared with traditional processes of scientific knowledge translation and stakeholder engagement (Flood et al. 2018; Wesselow and Stoll-Kleemann 2018; Edwards et al. 2019). Serious games are games with a purpose beyond entertainment, they are specifically designed to foster knowledge, collaboration, and action. As a collaborative tool, they enhance participatory social learning (Reckien and Eisenack 2013) and collective decision-making through players experimenting with different scenarios and options in a safe trial environment (Lawrence and Haasnoot 2017). These games often consist of physical components (such as cards or boards) and may be linked with computer interfaces or solely a computer or other physical component. They are recognised as a valuable intervention for enhancing learning across diverse communities of stakeholders, and for resolving value-laden and contested decisions (Taillandier and Adam 2018; Mossoux et al. 2016; den Haan and van der Voort 2018).

Although there are still relatively few games designed for climate change adaptation planning (Flood et al. 2018) previous researchers have established that games are a valuable tool for advancing knowledge and action regarding adaptative planning (Lawrence and Haasnoot 2017; Davies et al. 2021). A key attribute of climate adaptation games is that players simultaneously learn about the complexity of climate change and develop skills for navigating climate change adaptation (Lawrence and Haasnoot 2017). In particular, players recognise and work with deep uncertainty, multiple adaptation options, contested values and discover path dependencies (Lawrence and Haasnoot 2017). Perhaps the most significant finding is that serious games can encourage the consideration of, potentially innovative, alternative ways forward (Lawrence and Haasnoot 2017), and challenge people's existing beliefs about what strategies will work (Runmore et al. 2016). Experimentation with new strategies is encouraged because novel choices in the game don't have real consequences so failure occurs in a safe space (Krotoski 2010). 
From the above accounts of serious games, we hypothesise that serious games in an indigenous context could be a useful mechanism to bring together diverse knowledge, and provide a safe, culturally sensitive space, for participants to play (test) and evaluate different adaptation strategies for the Tangoio marae. ${ }^{1}$ Furthermore, from our experience in co-developing Marae-opoly, it suggests serious games lend themselves to being integrated with Mātauranga Māori, and while this is not a Māori-specific game, it does present a promising means to engage with this kaupapa. The first step we took to create an appropriate serious game is to be attentive to the context in which the game will be situated.

\section{Māori knowledge, engagement and climate change adaptation}

As researchers (predominantly pākehā-non-Māori- in our case) we are always tied to colonial histories and experiences of Māori and Māori places. There is a politics of engagement, representation and place, in every research encounter with Māori (Smith 2014; Stokes 1987; Coombes et al. 2014). While there is an extensive repository of research on Māori groups, much of it has a tainted history in terms of appropriation of indigenous ideas, the remarginalisation of indigenous groups, and the failure to engage with and give back research to these groups (see, for example, Walker 1990; Smith 1999; Bargh 2007). Embracing Smith's (2014) call to researchers — which may include pākehā_-to establish and re-build respectful relationships with indigenous groups with special emphasis toward creating ethical spaces of engagement, there is a growing set of examples in the literature, which document how researchers (Māori and pākehā) can be better guests in Māori worlds (see, for example, Thomas 2015; Fisher et al. 2015; Makey and Awatere 2018).

For Aotearoa New Zealand, the projected effects of climate change will be felt nationwide. Māori are especially vulnerable to the impacts of climate change. The effects will adversely affect Māori interests and resources and their social and cultural landscapes (Ministry for the Environment 2020; Reisinger et al. 2014). While the majority of Māori live in urban environments, they also occupy remote and rural areas where the economy and social and cultural systems are strongly tied to natural environmental systems (e.g. traditional resource use, tourism, fisheries, agriculture), and where vital infrastructure and services are vulnerable

\footnotetext{
${ }^{1}$ A marae is a sacred communal space that serves religious and social purposes in Māori society. Technically the marae ātea is the space immediately in front of the wharenui (meeting house) but the term is often used to include the complex of buildings around a central courtyard.
}

to extreme weather events (e.g. flooding, landslides, water services). The capacity of Māori to plan and respond to threats of climate change to their assets (i.e. buildings, farms, forests, native forest, coastal resources, businesses) varies greatly, often shaped by the relationality of Treaty of Waitangi $^{2}$ redress (or not), and is likely to be limited by access to funds, information and human capital, especially where there are large populations of Māori and increased risks of extreme weather (i.e. Tangoio marae). This means that marae and other Māori-owned assets will be affected, especially if they are situated near the coast or on flood plains (e.g., King et al. 2011, 2012, 2013). Simply waiting and reacting to an event or problems as they arise puts cultural assets and land at risk and jeopardises what is possible for future generations. As signalled by Māori authors, adaptation to these new climatic conditions will require additional financial resources, institutional change (i.e. decolonising institutions), and technological capacity that many Māori communities and businesses do not currently possess (Tunks 1997; King et al. 2011; Henwood et al. 2019; Parsons et al. 2019; Ministry for the Environment 2020; Reisinger et al. 2014).

There is an emergent field of Māori climate change and natural hazards science which has become increasingly significant in registering Māori knowledge and laying a basis from which to become sensitised to Māori practices, notions of vulnerability and perspectives of adaptation (e.g. Selby et al. 2010; Kanawa 2010; King et al. 2011; Bargh et al. 2014; Lambert 2015; Parsons et al. 2016; Smith et al. 2017; Parsons et al. 2019; Henwood et al. 2019). Beyond the literature published in journals, there is a significant conversation about how Māori could experience and might adapt to climate change ranging from the local level of whānau (extended family), hapū (kinship group, or sub-tribe) and iwi (tribal group) to national Māori organisations (e.g. Iwi Chairs Forum Climate Change Leaders Group, Te Ara Whatu, Federation of Māori Authorities, Te Wai Māori). Much of this knowledge is held in culturally appropriate spaces as well as in public documents, Māori postgraduate thesis and dissertations, and science reports. A common point expressed by Māori authors is the call for researchers to become progressive and responsive to Māori groups, their places, their knowledge, and their diversity of interests (e.g. people, places, cultural practices, species). As Parsons et al. (2019) suggest, the inclusion of indigenous knowledge and subsequent empowerment of indigenous decisions, may

2 The Treaty of Waitangi is the founding document of Aotearoa-New Zealand, it was signed in 1840 by the British Crown and 540 Māori chiefs. Historical breaches of the Treaty are dealt with via a complex settlement (redress) process managed by the Waitangi Tribunal (est 1975). As settlement typically provides resources to the claimant to redress historical breaches, where an iwi/hapu is in the settlement process affects the resources they can access to achieve collective goals. 
support in breaking and/or positively disrupting dependency on non-Māori institutions, to better formalising Māori governance, values and knowledge associated with adapting to environmental hazards. Recent research priorities include: identifying culturally appropriate strategies/approaches that can Māori institutions can utilise to adapt and respond to climate change and natural hazards, and establishing the key short to medium term priorities for Māori communities to respond to climate change and the pathways for implementation of strategies/approaches responsive to best mitigating climate change impacts (see, Awatere and Pirker 2018).

We take serious note of the diverse considerations presented above in an effort to establish a respective partnership in working for and with Māori groups. The emergent Māori scholarship and grounded efforts of Māori serve inspiration to endeavor to contribute to this project of empowering and resourcing Māori climate change adaptation (on their terms).

\section{Summary}

We draw from the above to sensitise ourselves toward codeveloping a serious game for indigenous climate adaptation. As the following sections show, we take up the invitation from a Māori group to be respectful and supportive guests, in which we follow their lead in framing what our contribution will be, to then co-develop resources for their adaptation journey.

\section{Context and methodology}

Located on the Te Ngarue Stream, Tangoio Marae is one of the worst flood zones in the Hawke's Bay, Aotearoa New Zealand. In short, regular floods are the norm for this steep catchment (HBRC 2005). Despite these flood events, the hapū lived in Tangoio area and built the first wharenui (meeting house) in the current marae location in the 1920's and a wharekai (kitchen and dining area) in 1955. However, as a result of a spate of devastating floods in the late 1950's and 1960's many whānau were forced to move away as their homes were damaged. The marae complex (wharekai, and wharenui) was repaired and is still used. Looking forward, the hapū (Marangatūhetaua/Ngati Tū, Ngāti Whakaari, Ngāi Tauira, Ngāti Kurumōkihi, Ngāi Te Ruruku, and Ngāi Tahu) and Maungaharuru-Tangitū Trust (MTT) aspire to build a proud, vibrant and modern marae for present and future generations. Fulfilling this aspiration requires careful and strategic consideration of the potential impacts of climate changes on the catchment, what this might mean for the marae and hapū, and what adaptation options might be possible.

Marae-opoly was developed as component of Te Huringa ki Te Rangi-He Rautaki Tāwariwari a collaboration between the people and hapu of Tangoio Marae, MTT and
NIWA. The overarching aim of the project was to develop an indigenous climate change adaptation decision model that captured the key processes and stages involved for the benefit of Aotearoa-New Zealand communities facing uncertain and complex climate change impacts. Maraeopoly was the platform used to integrate diverse information into a digestible format to enable the hapu to experiment with different strategies to achieve their desired adaptation outcomes. The following section describes both how the game was developed, run and used to create an adaptation pathway for the local context. We are deliberately non-specific on the content and outcomes of the game as that knowledge belongs to the hapu of Tangoio Marae and MTT. Finally, we reflect on our position as largely pākehā researchers, trained in western methods of enquiry, and how the Marae-opoly approach had a performative effect on shaping a better understanding of working with an indigenous group.

Marae-opoly was developed bespoke to its intended context. Game material was gathered by drawing together detailed local knowledge (i.e. hydrology, climate data, mātauranga hapū) and situated adaptation options and accurate contextual data to create a realistic experience for the hapū of Tangoio Marae. A mixed methods approach was applied in a staged process to gather and aggregate information into the components of Marae-opoly (Fig. 2).

\section{Articulating a shared vision and collective aspirations}

The process commenced in early 2016 and included three initial activities; reviewing existing documentation and strategic MTT plans to confirm their continued relevance; interactive group discussions (hui) at the marae; two online surveys. Each of the activities provided information on three key subject areas:

(1) Aspirations - dreams or hopes for the marae.

(2) Activities-behaviors and things the people wanted to do at the marae to achieve their aspirations.

(3) Built-form-spaces, structures, physical things and design features that support activities and aspirations.

Throughout the research, each Hui was organized and hosted by MTT as research partners and importantly all the Tangoio Marae community were invited to attend. Events were scheduled months in advance on a Saturday from $10 \mathrm{am}$ to $4 \mathrm{pm}$ to best facilitate the participation of all hapū members. For those members no able to attend in person, a follow-up online survey was constructed and made available for 17 weeks, which contained questions to enable participation in the development of a marae vision 
Establish the context in which the game is to be set

\section{Articulate objectives, aspirations and vision}

- What is the vision for the marae in the future.

- What does the marae need to flourish?

- What makes a functioning marae?

- What activities are important?

- What legacy do we want to leave our mokopuna?

\section{Understand past, present and future risks}

- What hazards are the community exposed to? Past present and future?

- What has been or will be the effect of these hazards?

- What will this mean for the objectives aspirations and vison?

What adaptation options exist - key trade-offs and opportunities

- What adaptation options exist?

- What are the limits of the options?

- What are the relative costs?

- What are the trade-off and opportunities? (\$ and other costs)

\section{Other critical factors}

- What other factors are relevant to the decision-making process?

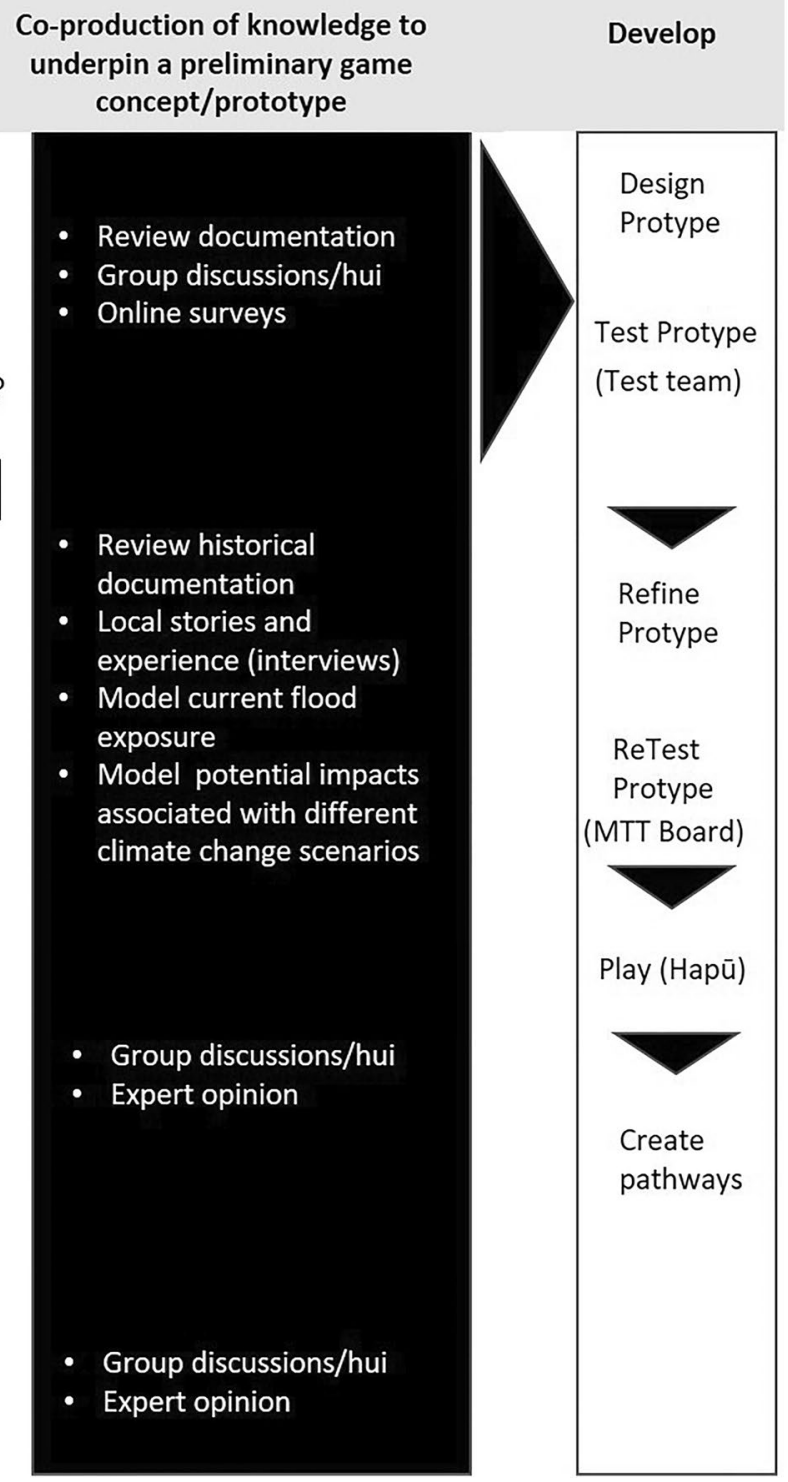

Co-production of knowledge to concept/prototype

Review documentation

- Group discussions/hui

- Online surveys

Review historical

documentation

Local stories and

experience (interviews)

exposure

Model potential impacts

associated with different

climate change scenarios

(MTT Board)

Play (Hapū)

Fig. 2 Serious game development process followed for Marae-opoly from inception to application

component and second a marae facility component. All the information gathered through hui and online survey were combined to establish the top priorities and aspirations for the Tangoio Marae community. Hui were co-designed and facilitated by predominantly Māori researchers following the appropriate tikanga (cultural practices relevant to place) of Tangoio Marae.

\section{Understand past present and future risks}

For Māori, the past is a basis to view the future, as expressed in the whakataukī_- "Kia whakatōmuri te haere whakamua" (My past is my present is my future, I walk backwards into the future with my eyes fixed on my past). As such, the development stage of Marae-opoly required considerable attention to cultivating a shared understanding of the past and current situation to ascertain an agreed foundation from which to consider and analyse possible marae futures and identify and develop appropriate adaptation options and pathways. To reflect this perspective, this step begins with understanding the past, considering the present and then looking forward.

Collection and collation of stories (mātauranga hapū) and experience of historical flooding in the valley were needed to help those who have never experienced such an event to begin to grasp the potential impacts and implications. To this end, kaumatua (hapū elders) and others with a long history of life in the area and some experience of flooding were approached to participate in semi-structured interviews (after Kitchin and Tate 2000; Flick 2009). MTT identified 
Table 1 Climate change scenarios used to investigate potential peak flood water levels in the valley and around Tangoio Marae

\begin{tabular}{lllllll}
\hline Scenario & Year & $\begin{array}{l}\text { Climate } \\
\text { change sce- } \\
\text { nario }\end{array}$ & $\begin{array}{l}\text { Assumed sea- } \\
\text { level rise }(\mathrm{m})\end{array}$ & $\begin{array}{l}\text { Peak discharge } \\
(\text { at marae })\left(\mathrm{m}^{3} / \mathrm{s}\right)\end{array}$ & Elevation model & Assumptions \\
\hline Bola & Present & None & None & 146 & No stopbank $^{\mathrm{a}}$ & Bridge blocked \\
Bola + Climate Change Scenario 1 & 2040 & RCP 6.0 & 0.2 & 154 & With existing stopbank Bridge blocked \\
Bola + Climate Change Scenario 2 & 2090 & RCP 6.0 & 0.5 & 164 & With existing stopbank Bridge blocked \\
Bola + Climate Change Scenario 3 & 2120 & RCP8.5 & 1.36 & 160 & With existing stopbank Bridge blocked \\
\hline
\end{tabular}

a The Bola modelling simulation assumed that the existing stop-bank constructed around the marae site was not in place. Future model scenarios retain the existing stop-bank around the marae site

${ }^{\mathrm{b}}$ The modelling assumes the main Te Ngarue Stream channel is blocked at the Tangoio Settlement Road bridge crossing. Stream channel blockage was observed at the crossing during the Cyclone Bola event and following smaller flood events as a result of forestry slash, logs and debris conveyed by runoff, erosion, and flood waters from the catchment

and recruited the participants and were involved in the design of the questions and the interviews. The interviews explored what floods the interviewees had experienced, what happened, what it was like to be in a flood, how it affected them and their surroundings, what the damage was and how the clean-up proceeded. With the verbal permission of the participants $(n=10)$, the interviews were videoed and transcribed. All interviews were transcribed, checked with the participants and returned to each participant as a printed document and voice recording to retain hapū knowledge for future generations. Where possible physical information on water depth (e.g., relative to door frames) and extent and duration of the flood water was obtained from participants to calibrate the hydrological-hydrodynamic models.

The present hazard and risk was constructed through hydrological hydrodynamic modelling of a historical extreme weather event, Cyclone Bola in 1987 (Bind et al. 2018). This event was chosen given the high likelihood of a similar event occurring again. The modelled peak water depths were calibrated using photographs in the Tangoio Valley during and after Cyclone Bola and compared with oral observations from whānau present at the marae either during Cyclone Bola or soon after the flood waters receded. Future flood hazard and risk were then explored using a coupled hydrologic-hydrodynamic model to provide a couple of points from which to start a conversation around the potential impacts of climate change on Tangoio Marae and surrounding areas. To this end, we used the model to assess the future hazard arising from climate change under two Representative Concentration Pathways (RCPs), RCP 6.0 and RCP 8.5 [5th Assessment Report (AR5) in 2014]. This was inclusive of projected sea-level rise impacts across a range of timeframes (short, medium and long-term), and future river flooding coupled with increases in sea-level increases of $(0.2 \mathrm{~m}, 0.5 \mathrm{~m}$ and $1.36 \mathrm{~m})$ across different climate change scenarios (See Table 1 and Bind et al. 2018). Three scenarios were modelled in this project to investigate the potential impacts that climate change could have on the peak flood water level in the valley and around the marae.

\section{Adaptation options}

A hui and hikoi (walk) in late 2016, presented the collated flood experiences and modelling data to prompt a hapū led brain-storming session to identify both adaptation options as well as options to upgrade existing facilities or build new ones that achieve collective aspirations. Around 40 participants attended representing a broad cross-section of the hapū. Expert opinion broadened the list and calculated the capital and maintenance cost of each option and the limits of their effectiveness in terms of flood mitigation. No option was removed so the hapu could recognize their contribution. Other factors that affect decision-making practices needed to be scoped for their inclusion into Marae-opoly including access to financial resources, costs of insurance, returns on other investment options and returns, land cost, and building costs.

\section{Game design}

Marae-opoly represents a simplified version of the realworld challenges faced by the hapu while retaining the key elements of real-world decisions (e.g., tensions between the choices, the opportunities, and the trade-offs, the range of choices). Additionally, several key climate change adaptation game concepts underpinned the design (after Lawrence and Haasnoot 2017), these included:

(1) Deep uncertainty associated with the timing and pace of climate change. We do not know when the impacts of climate change will be experienced, because we do not know what greenhouse gas mitigation will be achieved and what change is already "locked in"

(2) Adaptation options have engineering limits and do fail under certain conditions. For example, stop banks have 


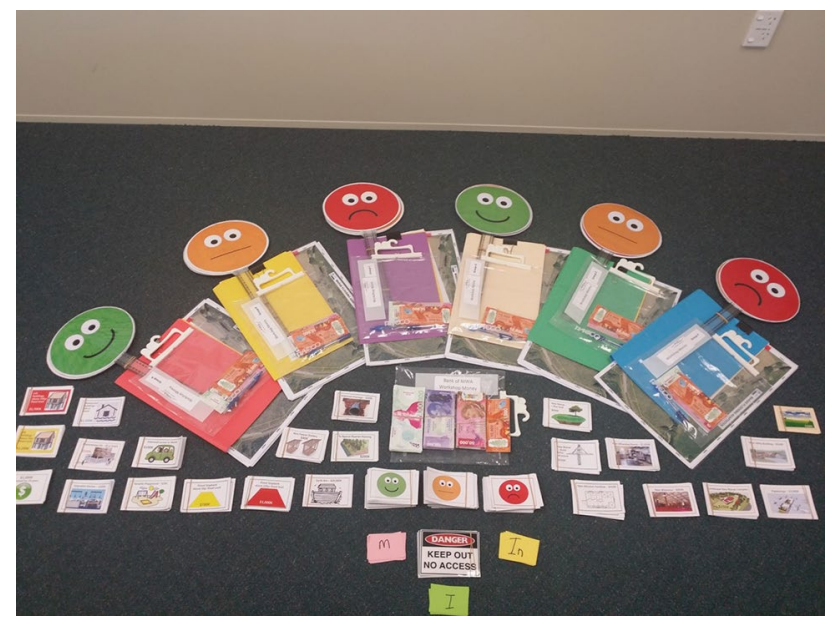

Plate 1 Co-designed game pieces (see, Colliar and Blackett 2018) engineering design limits that dictate the level of flood protection that can be achieved.

(3) Some adaptation options create path-dependency, effectively complicating a transition to other alternatives.

Before the hapu played the game, the game prototypes and key components (Plate 1) went through several iterations of testing and refinement first with the research team then second with MTT (Fig. 2).

\section{Gameplay}

A team of three facilitators introduced and played the game with hapū at a full day Hui in March 2017 organized by MTT and run at Tangoio Marae. Six small groups of between five and eight players, of mixed ages and gender were tasked with deciding how to adapt Tangoio Marae over 100 years of

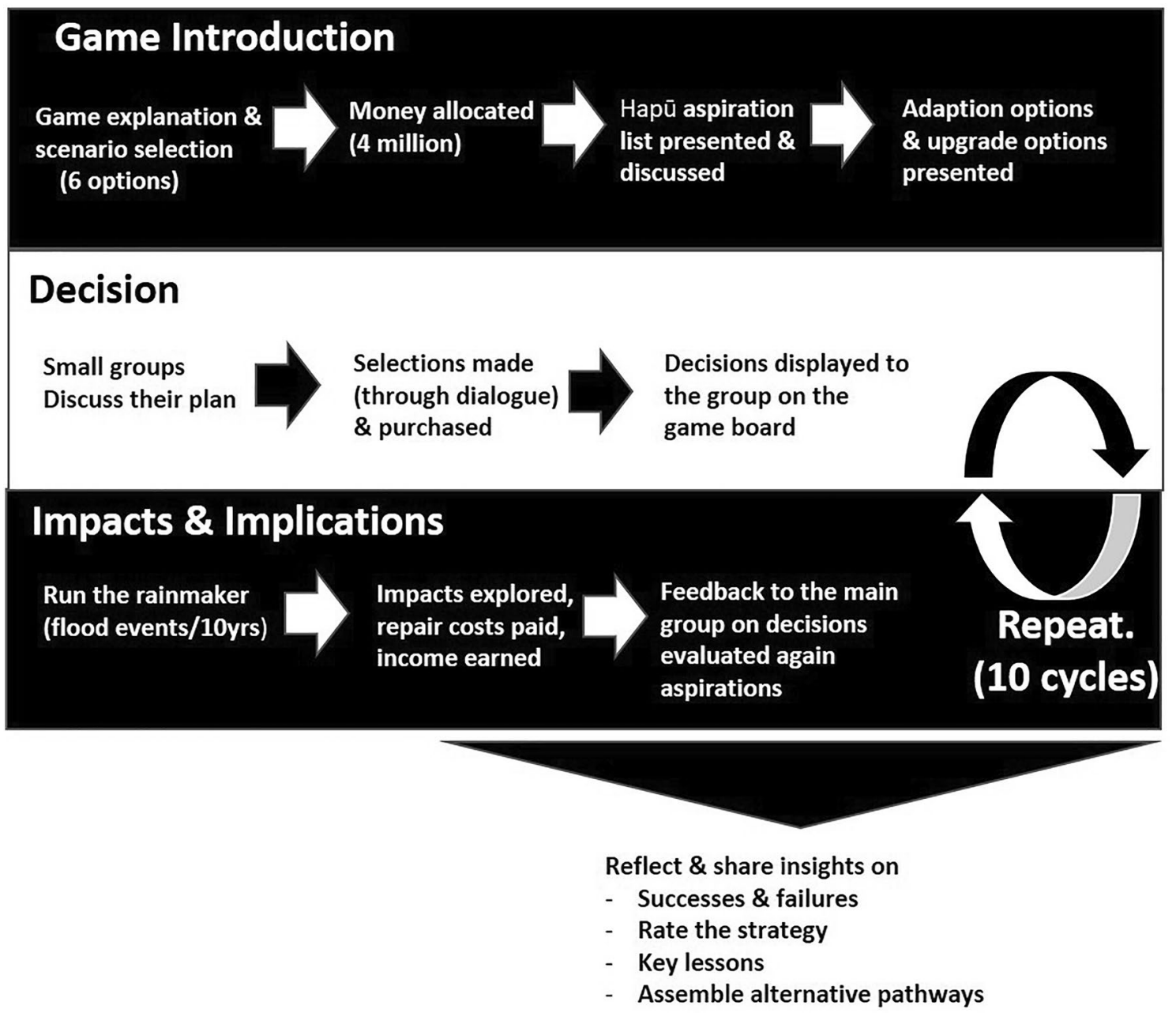

Fig. 3 Order of gameplay beginning with an introduction of how the game functions, followed by a decision-making phase and finished with the players experiencing the impacts and implications of their choices 
Fig. 4 Summary of a 10 year period indicating the frequency and magnitude of flood events generated by the rain-maker. The players experience 8 normal years with no substantive floods, a minor flood and a serve flood

\section{Rainfall Summary 2041-2050}
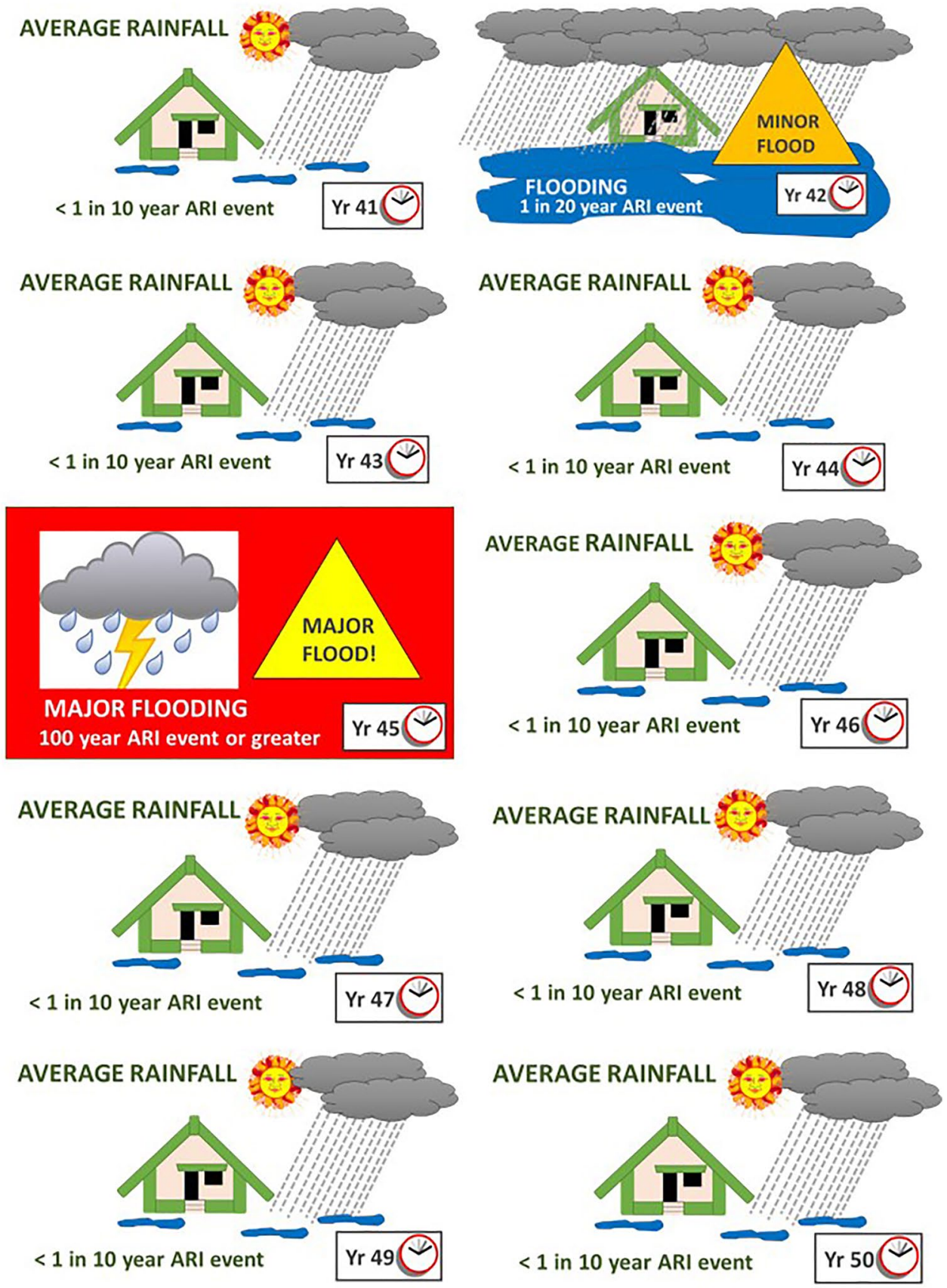

gameplay against a backdrop of increasing flood frequency and magnitude.

The game introduction (Fig. 3) involved an explanation of the nature of the flood hazard and risk, the funds realistically available to the hapu for adaptation (\$4million), the outcomes desired by the hapu (from the survey) and the range of options available. Players then collectively decided what actions (if any) to take, paid for the options (through a bank run by the facilitators). Once all choices were made, the "rainmaker" was activated to illustrate what flood events had occurred over a 10-year timeframe (the unit of gameplay). The rainmaker was a visual way to demonstrate different flood severities and frequencies and how these changed under different scenarios (possible futures) over time. There were six different rainmakers one of which was randomly selected at the beginning of the game. To approximate the uncertainty we will experience in reality, neither the players or the facilitators knew "which rainmaker been chosen" or 
Table 2 Post-game reflection questions

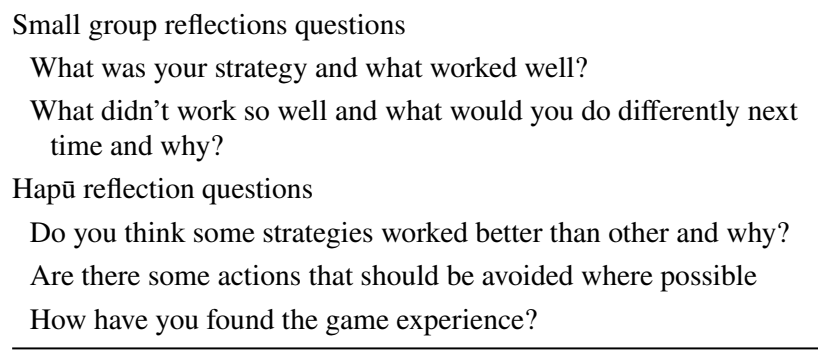

what sorts of changes could be experienced throughout the game (Fig. 4).

The choices made by each group determined what the impacts and implications round involved. Those who invested money received an income, those who brought insurance had repairs paid for, although all damage was mitigated by the adaptations in place. Once the facilitators had assisted with these often quite complex calculations, each group presented an evaluation of their decision against both the resulting flood damage and the hapū aspirations to other groups of players, which highlighted the choices ahead. This was a purposeful step to create a space of collective reflection on pitfalls and advantages of different alternative actions.

After the reflective discussions, the groups reentered the decisions phase. The decision and implications step was repeated for 10 cycles over 100 years. On completion, the small groups were asked to comment on the successes and failure of their strategy (Table 2), followed by a hapū discussion on what they had learned from others.

The research team collected notes for analysis from the evaluation sessions and individual evaluation ranking 11 statements on a 6 point Likert scale (strongly agree to strongly disagree) were distributed at the end of the game session. Keeping with the tikanga of Tangoio Marae, participants provided oral consent to participate in the evaluation. A basic thematic and numerical analysis were undertaken to establish if:

(1) the co-creation process created a realistic game that reflected the hapū's reality.

(2) if the game created a safe learning and experimental space for the hapū that is responsive to both culture and place.

(3) Was the game a useful way to package up information in a way that is empowering.

\section{Results}

Rather than the outcomes of the game hui, and the adaptation pathways specific to Tangoio Marae we focus on answering our three previously stated research questions.
The following section is built around the information gleaned from the post-game evaluation (Fig. 5), facilitator and MTT notes and observations.

Overall the post-game evaluation data suggest that Maraeopoly was very successful with at least $90 \%$ of respondents $(n=28)$ reporting a three or less for each of the questions asked (Fig. 5). This clearly demonstrates the value of codeveloping a fit-for-purpose, place-based serious game to create a learning environment where key discussions occur and safe experimentation is possible with different options.

\section{Does the co-development process create a realistic game that reflects the hapū's reality?}

Greater than $90 \%$ of respondents in the post-game evaluation survey reported seeing their thoughts and ideas reflected in the game and felt their ideas were valued. Further, both the MTT trust and the wider hapu rapidly engaged with the game, with no modifications, and used it to explore their desired strategies. Clearly, the co-development gamebuilding process incorporated the knowledge (mātauranga), thoughts, and ideas held within the hapū and wove this together into familiar and real narratives.

\section{Did the serious game (Marae-opoly) create a safe learning and experimental space for the hapū that is attentive to both culture and place?}

The game created space for experimentation with options and combinations of options over time- beyond the binary of a "stay in place" or "leave" one-off static choice.

"We learnt a lot, we realize now that this is a complex project, and understanding the mahi (work) involved it is not as simple as go or stay and that is what we thought, easy done, so realised that there is a lot to think about" (Spokesperson Group 6)

Most importantly the simulation game was fun.

"I enjoyed the game, I think we leave here with more knowledge" (Spokesperson Group 2).

\section{Was the game a useful and appropriate way to explore knowledges, perspectives and alternatives in a way that is empowering?}

Not only was additional knowledge acquired regarding the relative successes of different strategies enacted over time, there was time for conversations within and between groups (across generations and gender) over desired outcomes and how to achieve these. 
Percentages of hui attendees (March 2017) who agreed (1) or disagreed (6) with the statements presented

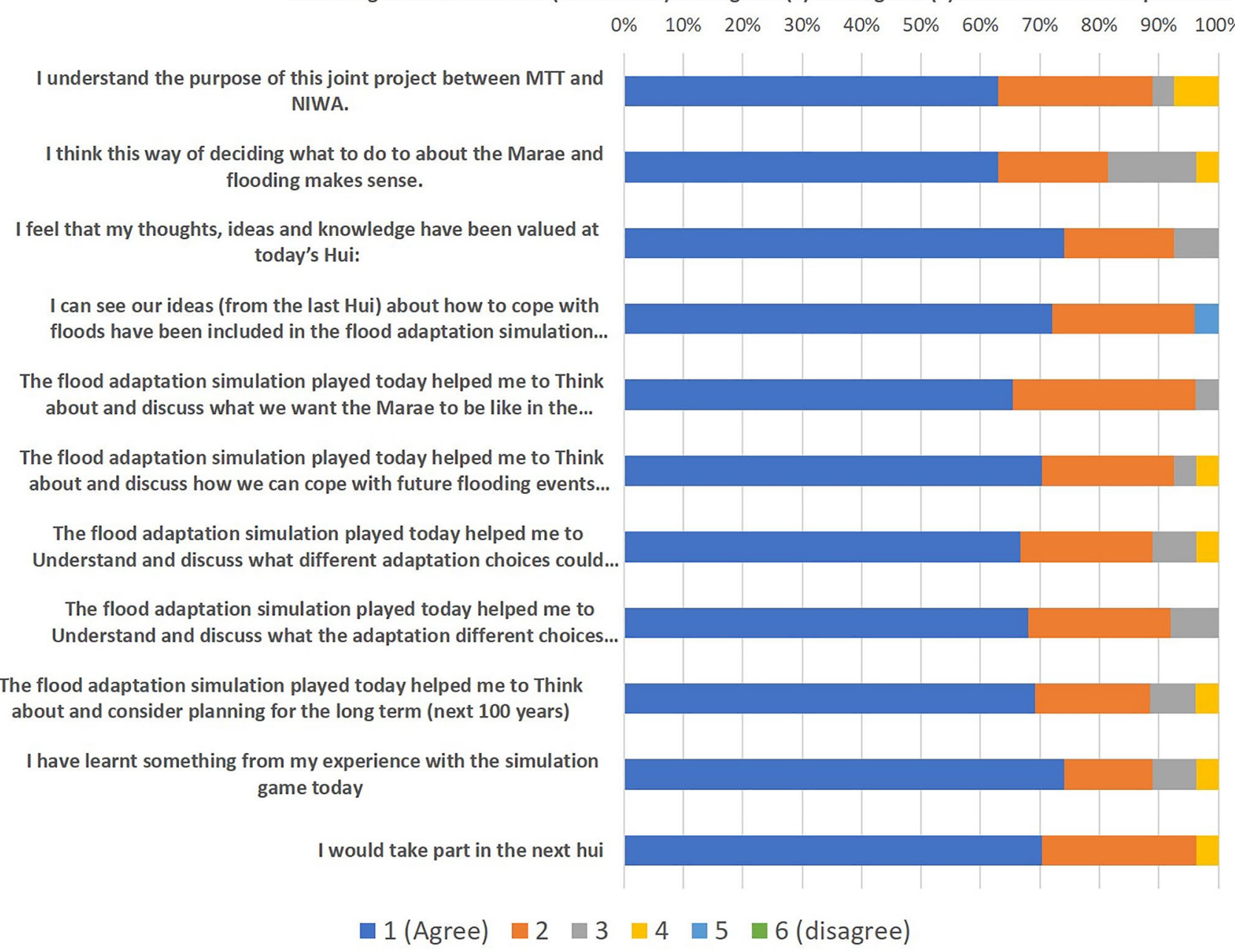

Fig. 5 Post-Game hui evaluation data $(n=28)$ showing the percentage of participants that agreed or disagree with the 11 evaluation statements

"We had a lot of fun, a lot of kōrero doing it. We are leaving here with our eyes wide open. (Spokesperson Group 6)"

"Different generations can be heard on this kaupapa as well, it is them (rangatahi) who will be dealing with this, they are important to this process". (Spokesperson Group 3)

Finally, but by no means least, after the game experience, all but one participant planned to remain engaged with the project and subsequent conversations and hui.

Overall, the results from the multiple threads of evaluation indicate the success of the methods in producing a game that clearly reflects the lived experience of the hapu and provided an enjoyable but challenging opportunity to experiment with possible futures. In short, the results confirm the validity and appropriate-ness of the methods. Furthermore, the permission and endorsement from MTT to share the experience of
Marae-opoly in a paper within this special issue to an international audience, suggests the research experience was a success.

\section{Discussion}

Our argument proposes that serious games have the potential to navigate tensions and co-develop climate change adaptation resources that can be situated within indigenous communities. Throughout the description of the methods and results, there is considerable emphasis on relationshipbuilding and the translation of knowledge into a meaningful marae-based resource. We do not propose an off-theshelf-game, rather we point to a process that has enabled an effective partnership with indigenous people and the co-development of a meaningful in-situ method to inform adaptation. The success of marae-opoly came from it being 
led and codeveloped by MTT and hapū members, they initiated the programme, framed the options in line with their priorities/aspirations, articulated other knowledge into their place, and played the game and deliberated adaptations in a culturally appropriate space (i.e. their marae). The following paragraphs discuss the authors' reflections on why the game design process produced a useful and usable game. We pay specific attention to the emergence of the research partnership, the evolution of research practices, process and methods, and how this enacted both place-based indigenous adaptation and principles for serious game development.

In 2015 the opportunity arose to fund climate changerelated research specific to iwi/Māori issues and concerns through the Deep South National Science Challenge, one of 11 New Zealand National Science Challenge research platforms. Leveraging the on-going relationship between the host research organisation and Tangoio hapū and MTT, a proposal to both address the flood risk challenge at Tangoio and advance adaptation research that could be applicable to other Iwi/hapū was co-developed. The project was framed according to MTT aspirations and framed upon self-determination in establishing appropriate adaptation options. As such, the research partnership was initiated by MTT, this meant traditional outsider 'researcher/practitioner' relationships became unsettled and MTT had agency over the project and researchers, its design and delivery were at the discretion of MTT. Throughout the description of results, there is considerable emphasis on relationship-building to co-produce knowledge relevant to game development. Once awarded, the project created a funded platform for the research team and MTT to actively engage in the process of co-producing knowledge. An emphasis on "funded" is a deliberate action because the payments to MTT supported their contribution and recognized the value of their involvement as active research partners. Without financial contributions, Māori groups can often remain the subject of research rather than active partners or must participate at their own cost, which often reproduces barriers to drawing on science services to support their climate change knowledge.

From the inception of the project, the intention was that this research would be a collective endeavor focusing on creating a conscious interface between different knowledges. Although the research team initially proposed most of the methods, MTT led this situated research process, stretching across key moments: gathering of knowledge and exchanges with kaumātua, through to the framing and selection of information for game development. Marae-opoly was tailored and pointed at matters of collective agreement amongst MTT and marae members.

It is evident from the methods that a considerable amount of time was taken to listen and understand the lived realities of the hapu and their aspirations for the future. To this end, we were able to weave the technical, social, cultural, and economic aspects into the game to create real and relatable storylines. A careful and sensitive data collection process attended to the narratives and mātauranga (knowledge) of the Tangoio hapū, which was fundamental to the success of the game. The game platform enabled the weaving of multiple knowledges and the creation of an appropriate forum to learn the various complexities.

The importance of applying research practices and methods that attend to and are sensitive to place cannot be understated. Through working in partnership, in-situ, the team were able to assemble different knowledge, across different times frames (past present and future) to create a game that reflected the current lived experience of participants as a platform to explore possible futures and facilitate situated decision-making. This was provided for by the use of place-based, participatory methods, in particular interviews, hui, hikoi, to collaboratively define and refine the parameters of the game and adaptation options within the game. This was provided by the use of place-based, participatory methods, in particular, interviews, hui, and hikoi, to collaboratively define and refine the parameters of the game and adaptation options within the game. These methods connect the theoretical pieces of the 'game space' with the physical marae space. The identified adaptation options were kept throughout the design process to maintain hapū ownership of potential solutions.

In combination, the research partnerships, process, and methods provided the base ingredients for successful project outcomes. Our practices enabled success in terms of supporting locally relevant adaptation while also demonstrating what serious games offer to indigenous adaptation decision-making and collective adaption decision-making more generally.

Marae-opoly allowed MTT and Tangoio hapū members to progress their adaptation conversation based on a new shared game playing experience. This is directly attributable to the enabling conditions for learning and considering options provided by Marae-opoly based on the novel place-based non-hierarchical combination of scientific, economic, and social factors woven together within the structure of the game (see also, Davies et al. 2021). These three evidence-based elements frame each of the climate change adaptation options for the context of Tangoio marae, thereby encouraging players to learn about and experiment with not just one, but all three components, in their decision making. Through this experience, previously unconsidered options were revealed.

While Marae-opoly game is specific to Tangoio Marae, the approach to its development provides more general principles and practices for working with indigenous peoples in efforts to develop tools for adaptation and decisionmaking (i.e. their initiative, their terms, their place-the researchers were guests to be guided by and support the 
marae). Indeed, the same set of place-based practices and behaviours can support bespoke games for any group with local climate change adaptation ambitions. It should be noted that although Marae-opoly can be used with other groups the absence of place attachment is likely to affect the players' actions and choices. This suggests that for a serious game to form the basis of localised adaptation pathways (e.g. DAPP's) they need to be (culturally) grounded in place. Although, this does not mean that outsiders cannot learn from the Marae-opoly experience, it just means that the new knowledge for another player will be more general in nature (see also, Davies et al. 2021).

As predominantly pākehā researchers, our analysis and evaluation of a game-based approach to climate adaptation is at the surface level of mātauranga Māori and presented through the lens of our own research cultures. However, we sought to understand culturally appropriate spaces to work with Tangoio Marae in ways in which supported hāpu learning and self-determination of results. Through listening deeply, we were able to position our own knowledge to interface with mātauranga Māori and empower Māori decisionmaking/adaptation to climate change. We did not seek to integrate their mātauranga into our project, rather they drew our researcher's knowledge into their space of understanding and decision-making. Being guests of MTT and Tangoio hapu and acting in the space of their land and marae fostered the repositioning of researchers as guests who were there to support Tangoio decision-making. As researchers, our typical fora of knowledge production and delivery were uplifted and articulated into cultural spaces and our acts were at the determination of our hosts.

\section{Conclusion}

In this paper, we described and analysed a serious games approach which was utilised by an indigenous group to support their decision-making on what they considered placeappropriate adaptations. In telling the story of how maraeopoly was developed and played it reveals the generative research components that led to notions of success for our partners.

Firstly, the research partnership was initiated by our partners - they led the approach and articulated us (as researchers) into their project of understanding climate change and identifying appropriate adaptations to fit aspirations. The significance of this relationality between 'researcher' and 'output' cannot be underestimated - as researchers we were enrolled by indigenous partners to achieve their defined 'output'. As a partnership, this helps redress the typical asymmetries between 'researcher' and 'researched'.

Subsequently, this shaped the second set of learnings on the research process. Our partners led the invitation for participation from the moments of knowledge gathering and playing Marae-opoly, furthermore, they set the parameters of what was appropriate (or not), this involved considerable time amongst researchers to listen and learn from partners, whereby our partners directed our actions and articulated knowledge for their context. From this perspective, our partners self-determined the way in which Marae-opoly would be created and how it would be used. The balance of both partnership and process led to what we (at least) observed as a productive moment of articulating diverse knowledges and co-producing knowledge together to address adaptation. Through the moments of relationship building and the process of co-development, different knowledges were brought together in a non-hierarchical manner-all knowledge had an equal place in the constitution of understanding climate change and suitable adaptations for Tangoio Marae. Similarly, the value of 'place' in relation to where research moments occurred (i.e. hui between partners, knowledge gathering, gameplay and deliberation of options, on marae) reiterates the significance of working with an indigenous group on their grounds. Marae-opoly was developed to be place-specific and played in a specific place (Tangoio Marae) whereby our partners played in and according to their cultural institutions.

What other learnings can be applied elsewhere in an commitment to empowering indigenous communities on their journeys of adapting to new climates? The findings above point to an approach in which plays of 'expert' become destabilised and reorientated toward being a resource for indigenous peoples. While the researchers were subjectqualified, our partners framed the context and then drew on researchers for their individual knowledge, which could create a wider picture for our partners. This required significant time in which researchers learnt by listening and reverted from 'adopting/incorporating indigenous knowledge' to learning how an indigenous group was going to adopt researcher knowledge. Furthermore, the serious game acted as a platform in which all knowledge was integrated evenly. Thereby, traditional performances of 'expert', knowledge production and delivery were transformed into a sense of sharing with and for indigenous groups rather than traditional transactional research practices.

Lastly, this points to the question of partnerships and co-producing knowledge with Indigenous peoples. The lesson from this research encounter and process of developing Marae-opoly suggests recognising that equality in partnerships between indigenous groups and researchers, pales in relation to following the direction of Indigenous groups when it comes to bringing into being postcolonial worlds and supporting Indigenous self-determination. An equal partnership does not go far enough to reconciling past abuses and empowering indigenous groups to set the terms of relationships with others. Furthermore, in terms of co-producing 
knowledge, indigenous groups may choose not to share all their knowledge as their interest may sit with bringing other knowledge to their knowledge. Non-indigenous researchers should welcome such an approach as it may facilitate a deeper engagement and help avoid reproducing power relationships. As indigenous scholars have argued these past few decades, these are not your worlds, though rather than disengage, the transferable learning across this emergent field of scholarship, is to be better guests, treat each indigenous adaptation partnership journey as unique, and follow the lead of the indigenous groups to serve their priorities.

Acknowledgements To the esteemed ones, the leaders of Tangoio Marae, the Maungaharuru-Tangitū Trust (Ngāti Marangatūhetaua, Ngāti Whakaari, Ngāi Tauira, Ngāti Kurumōkihi, Ngāi Te Ruruku ki Tangoio me Ngāi Tahu), to the Doohan family, the Hawkes Bay Regional Council. The project was funded by the Deep South National Science Challenge (DEPSV16201).

Funding The authors did not receive support from any organization for the submitted work.

\section{Declarations}

Conflict of interest The authors have no conflicts of interest to declare that are relevant to the content of this article. The authors declare they have no financial interests.

Ethical approval This research was approved through the NIWA human ethics process in 2016, in accordance with the Code of Ethics developed by the New Zealand Association of Social Science Researchers. More importantly the research was carried out with careful consideration, sensitivity, and commitment to ensuring consistency with the spirit and intent of Te Tiriti O Waitangi, the Treaty of Waitangi.

Open Access This article is licensed under a Creative Commons Attribution 4.0 International License, which permits use, sharing, adaptation, distribution and reproduction in any medium or format, as long as you give appropriate credit to the original author(s) and the source, provide a link to the Creative Commons licence, and indicate if changes were made. The images or other third party material in this article are included in the article's Creative Commons licence, unless indicated otherwise in a credit line to the material. If material is not included in the article's Creative Commons licence and your intended use is not permitted by statutory regulation or exceeds the permitted use, you will need to obtain permission directly from the copyright holder. To view a copy of this licence, visit http://creativecommons.org/licenses/by/4.0/.

\section{References}

Awatere S, Pirker J (2018) Future proofing Māori development opportunities: Huringa Rangi Huringa Oranga. Nga Pae o te Maramatanga. Website: Future Proofing Māori Development Opportunities: Huringa Rangi Huringa Oranga I Ngā Pae o te Māramatanga (maramatanga.ac.nz)

Bargh M (2007) Resistance: An Indigenous response to neoliberalism. Huia Publishers, Wellington
Bargh M, Douglas S, Te One A (2014) Fostering sustainable tribal economies in a time of climate change. N Z Geogr 70(2):103-115. https://doi.org/10.1111/nzg.12042

Barker A, Pickerill J (2020) Doings with the land and seas: decolonising geographies, indigeneity, and enacting place-agency. Prog Hum Geogr 44(4):640-662

Barnett J, Graham S, Mortreux C, Fincher R, Waters E, Hurlimann A (2014) A local coastal adaptation pathway. Nat Clim Change. https://doi.org/10.1038/NCLIMATE2383

Bathke D, Haigh T, Bernadt T, Wall N, Hill H, Carson A (2019) Using games to facilitate collaborative water management planning under climate extremes. J Contemp Water Res Educ 167:50-67

Bell R, Lawrence J, Allan S, Blackett P, Stephens S (2017) Coastal hazards and climate change: guidance for local government. Ministry for the Environment, Wellington

Bind J, Zammit C, Yang J, Goodier C, Colliar J (2018) Exploring Coastal Adaptation Pathways for Tangoio Marae: Modelling Assessment of Climate Change Impacts on Flood Extent and Level. NIWA Client Report. July 2018: 56

Colliar J, Blackett P (2018) Tangoio Climate Change Adaptation Decision Model: A process for exploring adaptation pathways for Tangoio Marae Prepared for Maungaharuru--Tangitū Trust and Deep South National Science Challenge. NIWA Client Report 2018242HN

Coombes B, Johnson J, Howitt R (2014) Indigenous geographies III: methodological innovation and the unsettling of participatory research. Prog Hum Geogr 38(6):845-854

Davies K, Davies B, Blackett P, Holland P, Cradock-Henry N (2022) Adaptive and interactive futures: developing a"serious game" for coastal community engagement and decision making. Re-envisioning the Anthropocene ocean.University of Utah (in press)

de Coninck H, Revi A, Babiker M, Bertoldi P, Buckeridge M, Cartwright A, Dong W, Ford J, Fuss S, Hourcade J-C, Ley D, Mechler R, Newman P, Revokatova A, Schultz S, Steg L, Sugiyama $\mathrm{T}$ (2018) Strengthening and Implementing the Global Response. In. Masson-Delmotte V, Zhai P, Pörtner H, Roberts D, Skea J, Shukla P, Pirani A, Moufouma-Okia W, Péan C, Pidcock R, Connors S, Matthews J, Chen Y, Zhou X, Gomis M, Lonnoy E, Maycock T, Tignor M, Waterfield T (eds) Global Warming of $1.5^{\circ} \mathrm{C}$. An IPCC Special Report on the impacts of global warming of $1.5^{\circ} \mathrm{C}$ above pre-industrial levels and related global greenhouse gas emission pathways, in the context of strengthening the global response to the threat of climate change, sustainable development, and efforts to eradicate poverty (in press)

den Haan R, van der Voort M (2018) On evaluating social learning outcomes of serious games to collaboratively address sustainability problems: a literature review. Sustainability 10(12):4529

Edwards P, Sharma-Wallace L, Wreford A, Holt L, Cradock-Henry N, Flood S, Velarde S (2019) Tools for adaptive governance for complex social-ecological systems: a review of role-playing games as serious games at the community-policy interface. Environ Res Lett 14:113002

Fisher K, Williams M, FitzHerbert S, Instone L, Duffy M, Wright S, Suchet-Pearson S, Lloyd K, Burarrwanga L, Ganambarr R, Ganambarr-Stubbs M, Ganambarr B, Maymuru D, Country B (2015) Writing difference differently. N Z Geogr 71(1):18-33. https://doi.org/10.1111/nzg.12077

Flick U (2009) Introduction to quantitative research, 4th edn. Sage, London

Flood S, Cradock-Henry N, Blackett P, Edwards P (2018) Adaptive and interactive climate futures: systematic review of 'serious games' for engagement and decision-making. Environ Res Lett 13(6):063005 
Ford J, Vanderbilt W, Berrang-Ford L (2012) Authorship in IPCC AR5 and its implications for content: climate change and Indigenous population in WGII. Clim Change 113:201-213

Ford J, King N, Galappaththi E, Pearce T, McDowell G, Harper S (2020) The resilience of Indigenous peoples to environmental change. One Earth 2(6):532-543. https://doi.org/10.1016/j. oneear.2020.05.014

Granderson A (2014) Making sense of climate change risks and responses at the community level: a cultural politic lens. Clim Risk Manag 3:55-64. https://doi.org/10.1016/j.crm.2014.05.003

Gorddard R, Colloff MJ, Wise RM, Ware D, Dunlop M (2016) Values, rules and knowledge: Adaptation as change in the decision context. Environ Sci Policy 57:60-69

Haasnoot M, Kwakkel J, Walker W, ter Maat J (2013) Dynamic adaptive policy pathways: a method for crafting robust decisions for a deeply uncertain world. Global Environ Change 23(2):485-498

Henwood W, Moewaka Barnes H, Moriarty E, Zammit C, McCreanor T (2019) Enhancing drinking water quality in remote Māori communities. MAI J. https://doi.org/10.20507/MAIJournal.2019.8.2.1

Hill R, Walsh F, Davies J, Sparrow A, Mooney M, Council CL, Wise R, Tengö M (2020) Knowledge co-production for Indigenous adaptation pathways: transform post-colonial articulation complexes to empower local decision-making. Global Environ Change 65:102161

Hiwasaki L, Luna E, Marcel J (2015) Local and indigenous knowledge on climate -related hazards of coastal and small island communities in Southeast Asia. Clim Change 128:35-56

Hawke's Bay Regional Council (2005) Te Ngaru Catchment Flood Hazard Study Asset Management Group Technical Report, Napier

Intergovernmental Panel on Climate Change (2018) Global Warming of $1.5^{\circ} \mathrm{C}$. http://www.ipcc.ch/report/sr15/.

Kanawa L (2010) Climate change implications for Māori. In: Selby R, Moore P, Mulholland M (eds) Māori and the environment: Kaitiaki. Huia Publishers, Wellington, pp 109-119

King DN, Dalton W, Home M, Duncan M, Srinivasan MS, Bind J, Zammit C, McKerchar A, Ashford- Hosking D, Skipper A (2011) Maori community adaptation to climate variability and change: examining risk, vulnerability and adaptive strategies with Ngāti Huirapa at Arowhenua Pā, Te Umu Kaha (Temuka), New Zealand. NIWA Client Report: AKL2011-015: 133

King DN, Dalton W, Bind J, Srinivasan MS, Duncan M, Skipper A, Ashford-Hosking D, Williams B, Renata H, Baker M (2012) Coastal adaptation to climate variability and change: examining community risk, vulnerability and endurance at Manaia Settlement, Hauraki-Waikato, Aotearoa- New Zealand. NIWA report AKL2012-029: 142

King DN, Dalton W, Bind J, Srinivasan MS, Hicks DM, Iti W, Skipper A, Home M, Ashford-Hosking D (2013) Coastal adaptation to climate variability and change: examining community risk, vulnerability and endurance at Mitimiti-Hokianga, Aotearoa[1]New Zealand. NIWA Client Report: AKL2013-022: 140

Kitchin R, Tate N (2000) Conducting research into human geography: theory, methodology and practice. Prentice Hall, Harlow

Klenk N, Fiume A, Meehan K, Gibbes C (2017) Local knowledge in climate change adaptation research: moving knowledge frameworks from extraction to co-production. Wires Clim Change 8(5):e475. https://doi.org/10.1002/wcc.475

Krotoski A (2010) Serious fun with computer games. Nature 466(7307):695-695. https://doi.org/10.1038/466695a

Lambert S (2015) Indigenous communities and disaster research. Third Sect Rev 21(2):31-48

Lambert S, Scott J (2019) International disaster risk reduction strategies and indigenous peoples. Int Indig Policy J. https://doi.org/10. 18584/iipj.2019.10.2.2
Latulippe N, Klenk N (2020) Making room and moving over: knowledge co-production, Indigenous knowledge sovereignty and the politics of global environmental change decision-making. Curr Opin Environ Sustain 42:7-14. https://doi.org/10.1016/j.cosust. 2019.10.010

Lawrence J, Haasnoot M (2017) What it took to catalyse uptake of dynamic adaptive pathways planning to address climate change uncertainty. Environ Sci Policy 68:47-57. https://doi.org/10. 1016/j.envsci.2016.12.003

Lawrence J, Haasnoot M, McKim L, Atapattu D, Campbell G, Stroombergen A (2019) From theory to practice: a timeline of interventions by a change agent with the developers and users of Dynamic Adaptive Policy Pathways (DAPP). In Marchau V, Walker W, Bloeman P (eds) Decision-making under deep uncertainty: From theory to practice. https://www.springer.com/us/ book/9783030052515

Lawrence J, Blackett P, Cradock-Henry N (2020) Cascading climate change impacts and implications. Clim Risk Manag 29:100234. https://doi.org/10.1016/j.crm.2020.100234

Leonard S, Parsons M, Olawsky K, Kofod F (2013) The role of culture and traditional knowledge in climate change adaptation: insights from East Kimberley, Australia. Global Environ Change 23:623632. https://doi.org/10.1016/j.gloenvcha.2013.02.012

Makey L, Awatere S (2018) He Mahere Pāhekoheko Mō Kaipara Integrated Ecosystem-Based Management for the Kaipara Harbour, Aotearoa New Zealand. Soc Nat Resour 31(12):1400-1418

Makondo C, Thomas D (2018) Climate change adaptation: linking Indigenous knowledge with western science for effective adaption. Environ Sci Policy 88:83-91. https://doi.org/10.1016/j.envsci. 2018.06.014

Medema W, Furber A, Adamowski J, Zhou Q, Mayer I (2016) Exploring the potential impact of serious games on social learning and stakeholder collaborations for transboundary watershed management of the St Lawernce River Basin. Water 8(5):175

Ministry for the Environment (2018) Climate change projections for New Zealand: atmosphere projections based on simulations from the IPCC Fifth Assessments, 2nd edn. Ministry for the Environment. https://www.mfe.govt.nz/publications/climate-change/clima te-change-projectionsnew-zealand

Ministry for the Environment (2020) National Climate Change Risk Assessment for Aotearoa New Zealand: Main report - Arotakenga Tūraru mō te Huringa Āhuarangi o Āotearoa: Pūrongo whakatōpū. Ministry for the Environment, Wellington

Mossoux S, Delcamp A, Poppe S, Michellier C, Canters F, Kervyn M (2016) Hazagora: will you survive the next disaster? - A serious game to raise awareness about geohazards and disaster risk reduction. Nat Hazards Earth Syst Sci 16:135-147

Parsons M, Fisher K, Nalau J (2016) Alternative approaches to codesign: insights from indigenous/academic research collaborations. Curr Opin Environ Sustain 20:99-105. https://doi.org/10. 1016/j.cosust.2016.07.001

Parsons M, Nalau J, Fisher K, Brown C (2019) Disrupting path dependency: making room for Indigenous knowledge in river management. Global Environ Change 56:95-113

Reckien D, Eisenack K (2013) Climate change gaming on board and screen: a review. Simul Gaming 44(2-3):253-271. https://doi.org/ 10.1177/1046878113480867

Reisinger A, Kitching R, Chiew F, Hughes L, Newton P, Schuster S, Tait A, Whetton P (2014) Australasia. In: climate change 2014: impacts, adaptation, and vulnerability. Part B: regional aspects. In: Barros V, Field C, Dokken D, Mastrandrea M, Mach K, Bilir Y, Chatterjee M, Ebi K, Estrada Y, Genova R, Girma B, Kissel E, Levy A, MacCracken S, Mastrandrea P, White L (eds) Contribution of working group II to the fifth assessment report of the intergovernmental panel on climate change. Cambridge University Press, pp 1371-1438 
Rouse HL, Bell RG, Lundquist CJ, Blackett PE, Hicks DM, King DN (2016) Coastal adaptation to climate change in Aotearoa-New Zealand. NZ J Mar Freshwat Res 51: 183-222

Runmore D, Schenk T, Susskind L (2016) Role-play simulations for climate change adaptation education and engagement. Nature Climate Change 6, 745-750

Selby R, Pataka J, Mulholland M (2010) Māori and the Environment: Kaitiaki. Huia Publishers, Wellington

Smith L (1999) Decolonizing methodologies: research and indigenous peoples. Zed Books, London

Smith L (2014) Social justice, transformation and indigenous methodologies. In: Rinehart R, Barbour K, Pope C (eds) Ethnographic Worldviews. Springer, Netherlands, pp 15-20

Smith H, Bryant M, Allan P (2017) Climate change adaptations for coastal farms: bridging science and Mātauranga Māori with art and design. Plan J 2(2):497-518

Stokes E (1987) Māori geography or geography of Māoris. N Z Geogr 43(3):118-123

Taillandier F, Adam C (2018) Games ready to use: a serious game for teaching natural risk management. Simul Gaming 49(4):441-470

Thomas A (2015) Indigenous more-than-humanisms: relational ethics with the Hurunui River in Aotearoa New Zealand. Soc Cult Geogr 16(8):974-990

Tschakert P, Barnett J, Ellis N, Lawrence C, Tuana N, New M, ElrickBarr C, Pandit R, Pannell D (2017) Climate change and loss, as if people mattered: values, places, and experiences. Wiley Interdisciplinary Reviews: Climate Change: 1-19

Tunks A (1997) Tangata Whenua ethics and climate change. N Z J Environ Law 1(1):67-123

United Nations (2009) State of the World's Indigenous Peoples. United Nations Secretariat of the Permanent Forum on Indigenous Issues. Available from: https://www.un.org/esa/socdev/unpfii/documents/ SOWIP/en/SOWIP_web.pdf. Accessed 11 Feb 2021

Walker R (1990) Ka Whawhai Tonu Matou: Struggle without end. Penguin, Wellington

Wesselow M, Stoll-Kleemann S (2018) Role-playing games in natural resource management and research: lesson learned from theory and practice. Geogr J 184(3):298-309

Whyte K (2018) Indigenous science (fiction) for the Anthropocene: Ancestral dystopias and fantasies of climate change crises. Environ Plann E Nat Space. https://doi.org/10.1177/2514848618 777621

Zurba M, Maclean K, Woodward E, Islam D (2019) Amplifying Indigenous community participation in place-based research through boundary work. Prog Hum Geogr 43(6):1020-1043. https://doi. org/10.1177/0309132518807758

Publisher's Note Springer Nature remains neutral with regard to jurisdictional claims in published maps and institutional affiliations. 